\title{
Fallacies in Decision Making From an Asian Perspective
}

\author{
Michael Sony, Namibia University of Science and Technology, Namibia \\ (iD) https://orcid.org/0000-0002-8003-5216 \\ Neeta Baporikar, Namibia University of Science and Technology, Namibia \& University of Pune, India \\ (iD) https://orcid.org/0000-0003-0676-9913
}

\begin{abstract}
Decision making is integral for organizational success, and for that, the basic tenet is rationality. Yet, no decisions in the workplace are purely rational. Irrational decision-making behaviours are the irrational beliefs of employees. Irrational employee behaviours can cause a billion dollar revenue loss. The purpose of this paper is to study the complex employee phenomenon of workplace irrational decision making and unearth its dimensions. Hence, this study is envisaged as a lived experience using interpretative phenomenological analysis. Participation was by 123 employees working in various capacities in Western India through theoretical sampling frame. The results indicate that it is a multidimensional phenomenon, and prominent are religious, pseudo-scientific, and sorcery-based behaviours. Thus, these findings can help the organizations to understand the irrational behaviours of employees and aid managers to recognize the decisions of their employees to mitigate the bias in irrational decisions.
\end{abstract}

\section{KEYWORDS}

Behavioural Decision Making, Decision Making, Irrational Behaviour, Psychological Biases, Psychological Decision Making, Workplace Superstition

\section{INTRODUCTION}

Irrational employee behaviours can sometimes cause cost huge financial losses for the firms (Scandura, 2015; Stuckless, Ford, \& Vitelli, 1995). Rational employee behaviour is encouraged in an organization, however, in reality, the employee behaviours/ decisions at work are made on the subjective experience of the employees (Khresna Brahmana, Hooy, \& Ahmad, 2012). In an organization, employee learn about their work by drawing casual inferences based on the observations and experiences in the organizations. Various events happen in an organization at the same time or in the same period. Sometimes employees tend to interpret this casually un-related event as related and change their behaviour. Irrational decision making is the tendency to decide a course of action based on the irrational belief of employees towards various phenomenon that is happening at the workplace. Such irrational behaviours are common in developing countries like India; however, potential exists that even in 
developed countries also irrational beliefs will play a role. This is a complex or multi-dimensional phenomenon. It may influence an employee's individual's perceived level of confidence(De Paola, Gioia, \& Scoppa, 2014). Irrational decision making behaviours, can change an assortment of human behaviours either positively or negatively( $\mathrm{Ng}$, Chong, \& $\mathrm{Du}, 2010)$.From the allocation of economic resources(Ng et al., 2010) to major personal events (Shermer, 2002), irrational decision making behaviours impacts different spheres of human behaviours.

Irrational decision making behaviours may be classified into two categories(Wiseman \& Watt, 2004). Positive irrational decision-making behaviours, which seek to improve one's welfare. To quote an example touching wood or wearing lucky charms or crossing fingers. A negative irrational decision-making behaviour is to guard against bad outcomes. The examples are being certain numbers e.g. 13, breaking mirrors etc. They further hypothesized that positive irrational decision-making behaviours may serve different psychological functions compared to negative irrational decisionmaking behaviours. Management literature has recently studied holistic behaviour of employees at work. Some recent studies on workplace spirituality reiterate the above facts(Michael Sony \& Mekoth, 2017). Irrational decision-making behaviours may also play a major role in understanding employees' worldviews and will especially explain the rationale behind decision-making. Modern organization and Management as rational have been a subject of critique and reflection from various prominent authors(Thomas, 2005).The rational image of the organization is an idealization. It is an expression based on a belief of what management should be and not on the reality that what management is. The classical management does explain the major activities of management, this does not mean managers at all-time engage in such behaviours. Nevertheless, there is more to management than these formally defined functions. Forecasting and planning, organizing, co-ordination, commanding and controlling though are important functions of management. However, the real understanding of management is contextual. Though researchers have studied the phenomenon of irrational decision-making behaviours, there is no study on irrational decision-making behaviours conducted at the workplace. In a workplace, employees are working towards fulfilling organizational goals and objectives. Irrational decision-making behaviours being an individual phenomenon may play a major role in the alignment of personal and organizational goals. Besides the stresses found at the workplace are different than usually found in society (Lazarus, 1995). Different employees respond differently to challenging and stressful situations at work and hence studying complex coping employee behaviour would be essential to gain holistic understanding of the employees. Thus, it is not possible to import previous studies to explain workplace irrational decision-making behaviours. As irrational decision-making behaviours is a lived-in experience, this study purports to investigate the lived-in experiences of employees with irrational decision-making behaviours. Further with the advent of artificial intelligence (AI) and the likely role it will play in future especially in managing organizations, it would be fatal to ignore the human fallacies which will certainly impact decision-making even if the process of decision-making is based on the newer concepts and models developed including AI. Thus the objective of this paper is to evaluate the irrational decision-making behaviours from the recipient's perspective and to develop a middle range theory from the data in terms of its dimensionality. The present study draws on psychology, organization behaviour, human resource and marketing literature to offer insights into the research questions: How do you define workplace irrational decision-making behaviours and what are the dimensions of workplace irrational decision behaviour. The study in the process will add to the knowledge and understanding of this complex employee phenomenon of irrational decision-making behaviours by exploring its dimensions. Hence, the focus is on examining workplace irrational decision-making behaviours in a detailed, contextualized way, focusing on the phenomenology of workplace irrational decision-making behaviours through a qualitative examination of accounts provided by employees in India who had considerable working experience. 


\section{LITERATURE REVIEW}

The literature review for this study is in three themes. The first is theme is irrational decision-making behaviours behaviour, secondly, magico-religious perspectives in management studies and the last, regarding workplace irrational decision-making behaviours behaviour as a fertile ground for research.

\section{Irrational Decision-Making Behaviours Behaviour}

An important manner employee learns about the work is by drawing causal conclusions based on their experiences at work and observations of the environment circumstances or in other words the environment at work. The time-space coincidence is events can lead to casual inferences e.g., turning on an electric switch and the lights or electric motor turning on or an employee becoming angry after being shouted at by customers are sometimes perceived as events which are causally related. The interpretation of causality of events is one of the essential principles of learning in complex environment. To learn about the complex world, we live in and to understand the physical laws and psychological principles governing the world we live in. The interpretation of causality of events plays a very imperative role (Patyal \& Koilakuntla, 2016). Such ability can sometimes easily make us to draw causal inferences, when the two events are merely coincidental or not at all related. The incorrect causal inferences lead to irrational or behaviours. In other words, people exhibit behaviours that are based on illusory causality in the environment (Su, Lee, Ding, \& Comer, 2014). For instance, employees who wear a colour of shirt may perceive it brings good luck or blowing on the dice before rolling may perceive that their blowing behaviour and rolling the desired numbers are related.

If after repeated trial, the blowing on the dice is by the desired outcome. The player may form an inaccurate conclusion about the behaviour. It may lead to a conclusion that a lucky outcome that does actually exist because of the antecedent event (Jha \& Nanda, 2013). When such random behaviour is followed by the desired result, it creates an illusory causality between the behaviour and the desired outcome. The person as a result, increases the frequency of that behaviour and a happening of desired outcome no matter how remotely is likely to reinforce or cement the causality. Therefore, the positive feedback loop strengthens the conditioning of these individual responses resulting in irrational decision-making behaviours. Even though we live in the modern world with all ultra-modern scientific gadgets, still there is an element in human beings which makes trust in this illusory causality (Chung \& Bemak, 2002). Employees working in modern workplace face dynamic work situations and there are some situations even beyond their control (Frazer Winsted, 2000) which may result in immense stress for employees (M Sony \& Mekoth, 2016). In order to adapt to such situations employees, sometimes resort to irrational decision making behaviours as means of adaptive or coping learning strategy (Thomas, 2005). Though such irrational strategies may lead to frequent errors, however in assessment as long as the occasional correct response occurs it carries a large fitness benefit (Quaid, 1993). In an organization there are numerable instances where in employees must resort to such imaginary correlations for events happening at work. Because it leads to simplification in understanding for decision making (Fincham \& Evans, 1999). The need to study irrational behaviour at work will lead to a better holistic understanding of humans at work (Pfeilstetter, 2017; Stueber, 2013).

\section{Magico-Religious Perspectives in Management Studies}

It baffles human imagination to consider modern management in line with magical and religious beliefs. From a western educated industrialized rich democratic perspective, magical and religious beliefs in management are medieval or rather superstitious. Magico-religious interpretation of management or rather an approach is rooted in social anthropology literature. Social anthropology is identified as study of primitive peoples in simple, pre-industrialized societies(van den Heuvel, Demerouti, Bakker, \& Schaufeli, 2013) .In such societies, there is a close link between magic and culture, and in turn, it will affect the social culture. Modern Anthropologist has studied it further in 
modern and contemporary societies after retaining some of its frameworks. Some important thoughts in this regard are human beings and societies face with certain fundamental common problems. These, in turn, give rise to the emergence of a variety of social practices, which serve to cope with them. The exact nature of social practices can vary from culture to culture. However, their classification can be together, as they are oriented to deal with fundamental problems. Such an idea of functional equivalence suggests that a given problem can be solved in multiple ways (Lang \& Leach, 1982).Hence, using this line of thinking management practice can be seen to be magical or religious approach, because it serves similar ends in modern society or organization as it had served among the primitive people.

Both magic and religion is in use as important tool to handle uncertainties in human lives. Use of to attain specific ends, such as curing the sick or bringing rain is also often used to deal with situations that are believed to be dangerous and important. An important question then is do employees indulge in such magic, religious, or irrational behaviours in modern organization? The saying that management is getting things done through people, therefore people forms an important link in management (Thomas, 2005) However, people also bring uncertainties in management. A dominant image of a manager is a rational professional. However, many management techniques require application of arcane procedures in belief that desired outcomes will follow. However, such techniques are sometimes like institutional myth or scared narratives, which are difficult to be tested. To quote some instances some see job evaluation an institutional myth. A sacred narrative which expresses deeply held beliefs which are beyond objective testing (Evered \& Selman, 1989). Similarly even hard techniques like business process reengineering can been as a magical search for salvation (Quaid, 1993). Techniques like six sigma or lean management is also described as a magic solution (Fincham \& Evans, 1999). Hence, like magic or religion such procedures have little direct bearing on outcomes. In other words, what such techniques provide is a sense of insecurity, uncertainty or fears of accusation etc. From a magico-religious perspective, these management techniques are not as a rational alternative, but as magical or religious techniques in rational form.

\section{Need for Research on Irrational Decision-Making Behaviours}

The magico- religious perspectives provides that management techniques are sometimes not a rational alternative and hence employees deal with uncertainties in a magical form. Näslund (2008), the magic is defined as "a body of techniques and methods for controlling the universe, based on the assumption that is certain procedures are followed meticulously, certain results are inevitable" (Naslund, 2008). What distinguishes magic from science is that they who use them rather the scientific approach follows a scientific method validate magical procedures. Irrational decision-making behaviours is the belief in knowledge of magical procedures, which does not follow scientific method of analysis. As such, employees working in organization indulge in such irrational decision-making behaviours. There is no conceptual clarity in understanding the belief of irrational decision-making behaviours and there is no literature, which studies the irrational decision-making behaviours as belief of employee's in terms of its dimensionality, antecedents and consequences. Beliefs are lived in experience and hence this study intends to study lived experience of employees who are superstitious at workplace to understand the complex employee phenomenon of workplace irrational decision-making behaviours. Interpretative phenomenological analysis (IPA) is considered pertinent method for this study as it aims to examine, the personal lived experience of employees who are irrational in their decision-making behaviours and how employees make sense of their experience (Eatough \& Smith, 2017). IPA is also interpretative in recognizing the role of the researcher in making sense of the irrational decision-making behaviours experience of participants. In addition, the learning of IPA is from the theoretical viewpoint of symbolic interactionism, which is concerned, with the construction of meaning within both the social and personal superstitious world of individuals. 


\section{METHODOLOGY}

The objective of the study design is to explore the lived experience of employees who irrational decision-making behaviours at workplace are to find answers to research questions stated earlier. The research question directed the researchers to design a study that explored the lived experience of being superstitious at workplace. Since the interpretative phenomenological research approach exists for this purpose, it was the design chosen for this study. The chosen method is both phenomenological and interpretative. Thus, IPA views the analytic outcome as resulting from an interaction between participant's accounts and the researcher's frameworks of meaning.

\section{Selection of Participants}

The selection of the participants is through personal contact using snowballing method. The approach was to have a casual discussion with potential participants and the nature of the research with its agenda explicitly expressed. The main criterion for participant's inclusion was participants themselves describing them to be having some sort of supernatural orientation for events happening at work place. Besides, they should be willing to talk in depth about their supernatural orientation. Hundred and twenty-three participants took part in this study: 69 males and 54 female participants in an age range from 24 to 51. Participants' mean age was 37.9 years (SD 5.2).All had a religious upbringing and belonged to Hindu (54.47\%), Christian (19.5\%) and Muslim (26.01\%) faiths. Participants signed a consent form and their names changed to protect confidentiality. All were Indians, 52 (43\%) was graduate, $19(15 \%)$ had a postgraduate degree, 19 (15\%) had a diploma in engineering and $33(27 \%)$ had $12^{\text {th }}$ standard qualification. The International Standard Classification of Occupations was used to classify the occupations, $27(22 \%)$ were classified as holding professional jobs, $19(15 \%)$ were senior managers or officials and 77(63\%) fell into the category of service, shop and sales workers. The mean duration of participants experience at Job was 12.7 years (range 4-16.5; SD 5.1 years).

\section{Interviews}

As per the research aims, IPA methodology provides flexible guidelines to be adopted by researchers (Eatough \& Smith, 2017). The authors with consenting employees at their homes to collect data conducted semi-structured interviews. Primarily questions focused on the experiences of the participants proximal to their belief in paranormal causality, supernatural orientation, good luck charms, evil eyes etc. Subsequently in-depth probing of each of these concepts in terms of its antecedents and consequents done. Participant opinions feelings and observations noted. The interviews were audio-recorded for enabling ease in transcription and the authors conducted the same. The names of participants were de-identified and assignment of pseudo names done.

\section{Analysis}

The analysis of the data is in several stages. In the first stage, many times reading of written account and the transcript of the participants to immerse in the data and to get theoretical sensitivity. During reading with due care notes or comments, which appear significant or interesting, noted in the transcript. In the second phase, the classification is to develop themes or concepts based on written account and transcript transformed into initial notes. However, looking after was there not to lose the construction between the participant's own words and the researcher's understandings. The third phase consisted of examining the emerging themes during the second phase and trying to cluster them together based on the conceptual likenesses. The emerging clusters then got an expressive label; the choice was selectively to convey the conceptual nature of the themes for each group or cluster. The checking of written account and the transcript is to ensure that the connection with what the respondents said upheld as the groups or clusters of themes starts developing. In the final stage, a tabulation of themes was undertaken and the same is in Table 1. The table depicts the structure of major themes and subthemes. 
Table 1. Master and sub themes of Irrational decision making

\begin{tabular}{|c|c|}
\hline Master themes & Sub theme \\
\hline \multirow{5}{*}{$\begin{array}{l}\text { Religion Based Irrational Decision-Making } \\
\text { Behaviours }\end{array}$} & Religious symbols or objects \\
\hline & Religious Rituals \\
\hline & Offering to religious places \\
\hline & Religious sacrifice \\
\hline & Religion based auspicious/ inauspicious events \\
\hline \multirow{5}{*}{$\begin{array}{l}\text { Pseudo-Scientific Irrational Decision-Making } \\
\text { Behaviours }\end{array}$} & Auspicious/inauspicious time \\
\hline & Auspicious/inauspicious days \\
\hline & Location of workplace \\
\hline & Colour of workplace \\
\hline & Objects in workplace \\
\hline \multirow{3}{*}{$\begin{array}{l}\text { Sorcery Related Irrational Decision-Making } \\
\text { Behaviours }\end{array}$} & Good luck charms \\
\hline & Evil eye warder \\
\hline & Sacrifices \\
\hline
\end{tabular}

This process is repetitive for every respondent. The second author meticulously conducted an audit of the first author's thematic analysis independently, to ensure that the themes identified were warrantable and wherever difference arose, the solution was through in-depth discussions. The percentage agreement method was used to calculate the interrater reliability was calculated for themes and master themes. The reason for using interrater agreement as percentage was because it was easy to use, and the number of evaluators were two.

\section{DISCUSSION AND FINDINGS}

Three super ordinate themes identified in the analysis are religious irrational decision-making behaviours, pseudo-scientific irrational decision-making behaviours and sorcery related irrational decision-making behaviours. A summary of the results is in Table 1, which describes the master and the sub-themes created from the participants' accounts. Sometimes participants wriggled to talk about their irrational decision-making behaviours experiences and the respondents felt anxious in trying to express what they intended by irrational decision-making behaviours the observation is in the way participants acted and vacillated with their words and the anxiety was implicitly as seen by researcher. Despite this unease, the researcher did not to put words in the mouth to ensure ease and independence was there for the participants. Thereafter, participants were able to find a way to talk about their irrational decision-making behaviours. The language by the respondents used ranged from traditional religious vocabulary to pseudo-scientific terminology However, the theme that featured in all accounts of participants and it provided the underlying thematic texture with its connection. Further to advance the quality of the examination, the criteria of trustworthiness in qualitative research adopted. The important aspects to be considered for trust worthiness are 1) credibility, 2) transferability, 3) dependability, and 4) confirmability (Payne, 2015). Credibility is the defined as the degree of subjective relevance of the interpretations of the participants and the degree of honesty of the data. This enhanced by inviting the respondents to review the transcripts and the ideographic descriptions recorded of the interviews. In addition, this also diminished selective perception and reactive effects, which may creep in during the interviews. The issue of transferability which is the possibility of applying interpretations to similar phenomena was done by collecting extensive 


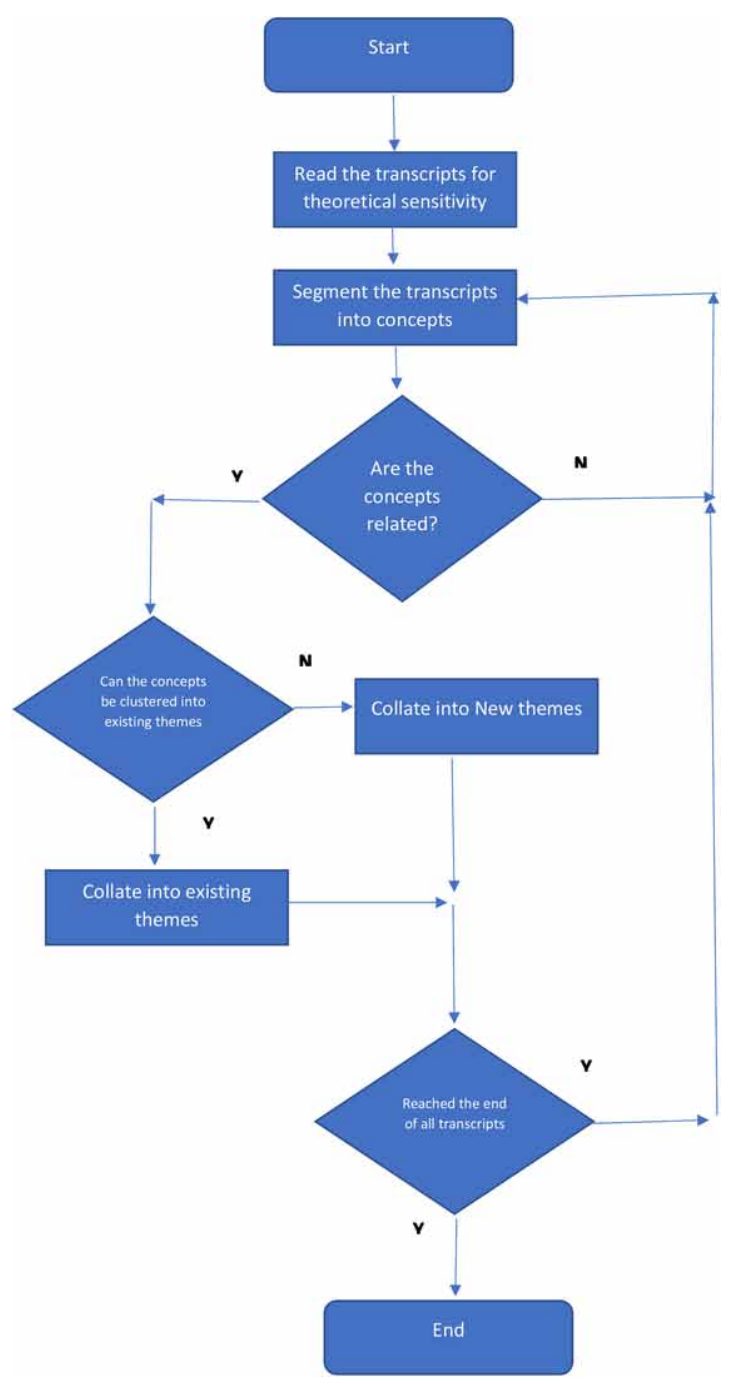

composite textural and structural descriptions of the respondents accounts (Lincoln \& Kalleberg, 1985). For addressing the issue of dependability, the level of similarity between the data, researcher's interpretations, and actual occurrences in the research setting, promoted by preparing, revising and documenting changes in the interview guide or plan and the subsequent plan is done. The issue of confirmability and the goal to provide a variety of relevant explanations to the studied phenomenon without bias was undertaken. The bracketing phase, which consisted to documenting an epoch of the phenomenon by the researchers before undertaking the analyses of the data, was resorted to arrest this issue.

\section{Definition of Irrational Decision-Making Behaviours}

The construct of irrational decision-making behaviours was developed and defined with respect to the attributes and categorization found in the data (Berdychevsky \& Gibson, 2015). Workplace irrational decision-making behaviours is the belief of employees that an event or object or a ritual at the workplace causes another favourable event at the workplace without any natural process linking the 
two events. It is belief of employees in supernatural causality for the events happening in workplace. The supernatural causality primarily revolves around three master themes that are religious irrational decision-making behaviours, pseudo-scientific irrational decision-making behaviours and sorcery related-based irrational decision-making behaviours. In addition, workplace irrational decision-making behaviours is a personal belief that rituals, objects, prayers, sacrifices etc. can change the outcome of unfavourable events into favourable events.

\section{Dimensions of Irrational Decision-Making Behaviours}

The following dimensions were unearthed during the qualitative study and elucidated below.

\section{Religion Based Irrational Decision-Making Behaviours}

The master theme religious irrational decision-making behaviours is the belief of employees that a religious event or religious object or religious sacrifice or religious ritual or offerings cause another favourable event at workplace. The participants irrespective of religious faith or denomination were of the view that religious symbols or objects bring in favourable outcomes of events happening at work place. The religious symbols most used were photographs of gods/ goddesses or prominent religious character of major religions. The objects were two or three-dimensional representations of the religious characters or events like Lord Ganesha, Jesus Christ, Cross or Om Symbol etc. Pictorial or symbolic representation of religious characters is believed to bring good fortunes (Dowling, 2007). These symbols are also being viewed as harbingers of happiness (Fingesten, Lehner, \& Whittlesey, 1975) and wealth(Koehn, 1954). Especially when there is a large variation regarding the outcomes of an event, than, such religious symbols or objects are thought to bring good luck(Barber, 1964). Another prominent sub theme that surfaced is religious rituals. A religious ritual is series of action performed in a sequence revolving around a religious character, place of worship etc. Participants were of opinion that these rituals bring in good luck for them at work place. Rituals are transforming abstraction of religious concepts to concreteness. In other words it forms an important tenet of cognitive experience of religiousness (Binde, 2007). Rituals like breaking a coconut before undertaking a major venture is considered as an auspicious ritual which is supposed to bring in good luck (Barrett, 2007). Religious worship of gods like Satyanarayana Pooja is an important event, which is supposed to bring in or cause favourable events for the individual or workplace. The participants that it will bring in good fortune in business felt offering monetary and non-monetary objects like banana, incense sticks, blanket, wax idols etc. Some participants also felt to offer to the deity near the workplace as it brings wealth and peace. In Indian culture the acts of offering proceeds from income to religious shrines has been a common on phenomenon (Klostermaier, 2014) Even people travel to long distances to offer proceeds to various gods and goddesses. The religious e-commerce in India is also on the rise. Various Banks have also started online system wherein customers can pay proceeds to religious places on line (Mitchell \& Bhardwaj, 1975). Similar trend is also there among the employees who wanted to offer the proceeds in the hope so that they bring in good luck.

Some participants after consulting some personal religious Gurus also indulge in animal sacrifices if they are not doing well professionally. Animal is offered in India as thanks giving ritual as well as to ward of bad luck (Samanta, 1994). Participant also felt to sacrifice animals to ward off bad luck at their work places. Some participants also indulged in fasting on auspicious days to bring in good luck for them at work. Some religious-based auspicious days were make important deals. The impact of social significance of auspicious days is paramount in the society (Smith \& Doniger, 1989). An interesting research was the increase in buying behaviour during auspicious days (MEHTA, 1997) and even healthcare sector also reports the demand for the increase in caesarean (Rengasamy et al., 2003). Even employees wherever possible try to schedule major business events based on religiousbased auspicious events. Employees spoke of different themes of religious irrational decision-making behaviours. Given in Table 2 are illustrative quotes. 
Table 2. Illustrative quotes representing different themes of religious based irrational decision-making behaviours

\begin{tabular}{|c|c|}
\hline \multicolumn{2}{|r|}{ Religious based irrational decision-making behaviours } \\
\hline $\begin{array}{l}\text { Religious } \\
\text { symbols or } \\
\text { objects }\end{array}$ & $\begin{array}{l}\text { "Having my family deity photograph near my desktop makes me feel as if I am being watched by him. I } \\
\text { feel a sense of being protected and feels I shall overcome any thing with his company" Participant } \mathbf{6 5} \\
\text { "I work a cashier, if I make a mistake, I need to pay it from my pocket. I try to stick a sticker of my } \\
\text { favourite God on my table. It makes me secure and I feel he is protecting me, and I make less mistakes." } \\
\text { Participant } \mathbf{5 8} \\
\text { "I have put a small statue of St. Francis Xavier on my table. Whenever I look at it, I feel nice and my } \\
\text { worries, my insecurities, my apprehensions all evaporate" Participant } \mathbf{3 1} \\
\text { "I have kept a small Shiv Linga near the lathe machine. I feel by keeping it near the place of work I get } \\
\text { energy to work and I make less mistakes" Participant } \mathbf{1 2 3} \\
\text { "I keep a small rosary and bible with me while at work. Though I do not read it but it makes me } \\
\text { confident that some supernatural is with me" Participant } 27\end{array}$ \\
\hline $\begin{array}{l}\text { Religious } \\
\text { Rituals }\end{array}$ & $\begin{array}{l}\text { "Before I start my work, I always chant Hari Om. This has been my practice since last } 20 \text { years. On } \\
\text { Mondays I make it point to light a incense stick near Lord Ganesha image at the entrance of my office" } \\
\text { Participant } \mathbf{1 1 1} \\
\text { "I put a flower on the statue of Jesus which I have kept near my workplace after cleaning the statue with } \\
\text { holy water." Participant } \mathbf{5 8} \\
\text { "I light incense stick every day and apply shringar on my deities image as I feel it will bring me luck and } \\
\text { prosperity" Participant } \mathbf{1 2 2} \\
\text { "I bow my head in deep respect on the small idol of Lord Ganesha kept near the entrance of my office." } \\
\text { Participant } \mathbf{7 6} \\
\text { "The annual Pooja in the office is a grand affair. We make it a point to attend the Pooja no matter where } \\
\text { we are. This is very important as it helps to ward off evil eyes and bring good luck" Participant } \mathbf{4} \\
\text { "I light a small lamp near Lord Ganesha's idol and offer flowers near idol at workplace" Participant } \mathbf{6 4} \\
\text { "Before I start a new machinery I break coconut as I feel it will bring me good luck and this piece of } \\
\text { machinery will be profitable" Participant } 90\end{array}$ \\
\hline $\begin{array}{l}\text { Offerings } \\
\text { to religious } \\
\text { place }\end{array}$ & $\begin{array}{l}\text { "We try to collect some money among ourselves and offer it to the temple near our workplace. I believe } \\
\text { this brings prosperity" Participant } \mathbf{8} 7 \\
\text { "I contribute some proceeds of our salary to the temple donations. There was a time when I could not } \\
\text { give much money and that year I did not get any increment. Even a disciplinary action was taken against } \\
\text { me" Participant } \mathbf{6 1} \\
\text { "I regularly make it a point to offer coconut and bananas near the temple which is near the workplace. I } \\
\text { feel that is the nearest God which protects us at work" Participant } \mathbf{8 0} \\
\text { "I visit the church near my workplace during the church feast and offer some proceeds with the hope } \\
\text { that it will bring me good luck. When I have a bad day at work the next day, I light candles at church. } \\
\text { This is a warning bell by God" Participant } \mathbf{3 6}\end{array}$ \\
\hline $\begin{array}{l}\text { Animal } \\
\text { sacrifice }\end{array}$ & $\begin{array}{l}\text { "Sometimes when I am not doing well professionally, I consult my Guru or Pandit and he tells me to } \\
\text { offer some animal to religious places. I offer it to get good luck charm" Participant } \mathbf{8 3} \\
\text { "I sacrifice cock to village deity for any problems at work. I have been doing it for quite a sometime and } \\
\text { I tell you it works. But if you ask me how it works, I cannot tell you but it works for me" Participant } 47\end{array}$ \\
\hline $\begin{array}{l}\text { Religion } \\
\text { based } \\
\text { auspicious/ } \\
\text { inauspicious } \\
\text { events }\end{array}$ & $\begin{array}{l}\text { "I fruit fast on certain auspicious days. I feel that if I do not fast on these days, something bad will } \\
\text { happen at work. Sometimes I work very hard on that day as it brings in good luck "Participant } \mathbf{1 8} \\
\text { "Tuesday is my deity's day I feel I am more productive on this day. I try to schedule meetings which ever } \\
\text { I can on this day. I work very hard on this day as I feel my chances of success is very high on this day as } \\
\text { my deity brings me good luck" Participant } \mathbf{3 3}\end{array}$ \\
\hline
\end{tabular}

\section{Pseudo-Scientific Irrational Decision-Making Behaviours}

The master theme Pseudo-Scientific irrational decision-making behaviours is the belief of employees that a time or day or location and colour of workplace or objects in workplace which according to some pseudo-science can cause a favourable event at the workplace. The participants in this study stressed on the importance of auspicious time. According to the birth time and birth place astrology predicts auspicious and in auspicious dates and times (Lo, 2003). In this study also, the participants expressed the importance of auspicious days and time. As far as possible, participants preferred to 
perform important work-related activities, as per this pseudo-science. Another sub theme that surfaced in this research is the participant's belief is the location of the workplace. Though workplace designing is a complex concept, however, the employees seem to be concerned about the direction the employee faces at work, the location of conference rooms etc. Such responses from participants confirm the views taken by(Methuen, 2011) where in it is believed by some followers of this pseudo-science that by locating/ positioning places one attains peace and prosperity. Different colours of walls, desks etc. believed to invoke prosperity. The participants in this study also expressed the impact of colours of the workplace on their performance at workplace. Some work according to them promotes prosperity. Certain objects like silver coins etc. considered in various cultures to bring good luck. In India, there is a tradition of putting small silver in the hands of new-born with a belief of bringing good luck (Ananth, n.d.). Some cultures also promote objects like the statue of laughing Buddha is considered to bring good luck (Anderson, 1921). The participants in this study explicitly stated the importance of object that promotes good luck for them and their company. The object varies from various metallic pieces to statues of various sizes. Employees spoke of different themes of pseudo-scientific irrational decision-making behaviours. Table 3 gives illustrative quotes.

\section{Sorcery Related Irrational Decision-Making Behaviours}

The master theme sorcery related irrational decision-making behaviours is the belief of employees that following the advice of certain individuals with mysterious power can cause favourable events at workplace. The Subthemes that surfaced in this category are good luck charms, evil eye warders, and sacrifices. Good luck charms are objects given the persons with mysterious powers, which will attract good fortunes. Some participants described extraordinary success at workplace, due to good luck charms gave by the persons with mysterious power. Kudler (2012) has described the society's belief towards certain people with mysterious powers. Sorcery related is further described by them

Table 3. Illustrative quotes representing different pseudo-scientific irrational decision-making behaviours

\begin{tabular}{|c|c|}
\hline \multicolumn{2}{|r|}{ Pseudo-Scientific irrational decision-making behaviours } \\
\hline Auspicious/inauspicious time & $\begin{array}{l}\text { "I consult astrologer before I take major decisions. I take his advice of on the } \\
\text { importance of time". Participant } \mathbf{2 5} \\
\text { "Before starting a project, I usually consult an astrologer for auspicious time" } \\
\text { Participant } \mathbf{1 0 3}\end{array}$ \\
\hline Auspicious/inauspicious days & $\begin{array}{l}\text { "Before an important meeting I usually see that I schedule it on an auspicious day" } \\
\text { Participant } \mathbf{8 6} \\
\text { "I believe that I cannot be at my best during inauspicious days as it influence of stars } \\
\text { may bring bad luck" Participant } \mathbf{2 8}\end{array}$ \\
\hline Location of workplace & $\begin{array}{l}\text { "I try to design my workplace as per the advice of vaastu shastra" } \\
\text { "While buying new plots I always try to buy Shermukhi plots and I believe it will } \\
\text { make my business prosper" Participant } \mathbf{4 5} \\
\text { "I have put conference room towards north west direction, and I have seen the results } \\
\text { in a such a short time" Participant } \mathbf{1 1 6}\end{array}$ \\
\hline Colour of Workplace & $\begin{array}{l}\text { "I have painted customer longue in blue color and within a short time I have seen my } \\
\text { business prosper" Participant } \mathbf{3 0} \\
\text { "The conference rooms are painted in green colour and I have observed that after } \\
\text { that I have started getting results" Participant } 39\end{array}$ \\
\hline Objects in Workplace & $\begin{array}{l}\text { "I keep few silver coins in office and it attracts more wealth for me" } \\
\text { "I keep the statue of laughing Buddha near the entrance at the entrance of my office } \\
\text { as it bring more wealth" Participant } \mathbf{8 4} \\
\text { "The first money I receive each day from the customer is placed in an empty place as } \\
\text { I have seen it attracting more wealth" Participant } \mathbf{1 1 4} \\
\text { "I keep a small silver key in my office because it attracts wealth" Participant } \mathbf{1 5}\end{array}$ \\
\hline
\end{tabular}


as the expression of a malign power in a person's body (Kudler, 2012). Respondents were also equally concerned in addition to bringing good luck charms, the existing evil eye should be warded off (Stewart \& Strathern, n.d.). For this, participants have reportedly visited people with mysterious power for remedies, which help in warding off the evil eye. Stewart and Strathern (2004) have reported the influence of evil eye in the daily lives of Indian society. Not only human beings even animals like horses are thought to be susceptible to evil eye (Mayer, Lewis, \& Barnouw, 1959). Such belief pattern in the society explains why even educated employees have some orientation towards sorcery related -based science. Sacrificing animals for favourable events are very common in India. Respondents also stressed the importance of sacrificing certain animals like cock or lamb not for religious reasons, but at the instance of tantric or persons with mysterious powers. Lykiardopoulos (1981) reported some instances of animal sacrifices in India at the instance of tantric. Such examples further strengthen the belief expressed by the respondents at work places in order to bring prosperity or good luck (Lykiardopoulos, 1981). Employees spoke of different themes of sorcery related irrational decision-making behaviours. Table 4 gives illustrative quotes regarding sorcery related irrational decision-making behaviours.

\section{CONCLUSION}

The current study is in the context of the employees who are take irrational decision making in India. Through an interview approach and review of related literature on general irrational decision-making behaviours and paranormal belief, this study not only identified the dimensions of workplace irrational decision making. A moderating factor was also identified which in help in understanding the concept of workplace irrational decision making. This study is a first attempt to provide the dimensions of workplace irrational decision making. The three dimensions of workplace irrational decision making were religious irrational decision-making behaviours, pseudo-scientific superstition, and sorcery related irrational decision-making behaviours. Besides various subthemes in each of the dimension extends the study and provides a substantive theory. To conclude, the contribution of this study lies in addressing the concept of workplace irrational decision making, believed to be more prevalent among various types of employees. This study reveals that the topic of workplace irrational decisionmaking needs serious consideration and not treated in a trivialized manner, as it is an intricate and multifaceted issue tied to employee's belief system, as well as job satisfaction and job performance, indicating that what happens at work may spill over into everyday life. The theoretical contribution of

Table 4. Illustrative quotes representing sorcery related irrational decision-making behaviours

\begin{tabular}{|c|c|}
\hline \multicolumn{2}{|r|}{ Sorcery Related Irrational Decision-Making Behaviours } \\
\hline Good luck charms & $\begin{array}{l}\text { "I visit a well-known baba and he gives me a blessed ash to be kept at the work place and it } \\
\text { attracts good luck" Participant } \mathbf{4 8} \\
\text { "A blessed egg by my favourite Bengali Baba bring in all the good fortunes and I am } \\
\text { extraordinarily successful at workplace" Participant } \mathbf{9 8}\end{array}$ \\
\hline Evil eye warder & $\begin{array}{l}\text { "Lemon and green chilly is hung in my office as wards of evil eyes" } \\
\text { "A Guru has given me a small statue after blessing which I need to keep on my desk. After } \\
\text { I started using it I have got results and I have become very successful in the company" } \\
\text { Participant } \mathbf{8 4} \\
\text { "I wear an evil eye protection amulet which helps me to ward off evil eyes which helps me to } \\
\text { perform well" Participant } \mathbf{5 1}\end{array}$ \\
\hline Sacrifices & $\begin{array}{l}\text { "I offer sacrifices of a cock for my guru who helps me to outshine my rivals at workplace. } \\
\text { Whenever any bad things happen at work I offer sacrifices of cock "Participant } \mathbf{2 0} \\
\text { "Off the late I was incurring a heavy loss in business. I was doing badly and I met a baba } \\
\text { who advised me to offer sacrifice of a lamb and then onwards things changed very rapidly" } \\
\text { Participant } 35\end{array}$ \\
\hline
\end{tabular}


the study is that this study has conceptualised the dimension of workplace irrational behaviours. The academia will benefit by understanding these dimensions and appropriate scale can be developed to measure it. This study will further the knowledge of decision making and its socio-cultural relevance in understanding the process of human decision making. Even though in the modern organizations artificial intelligence and Industry 4.0(Michael Sony, 2018; Michael Sony \& Naik, 2019) may dominate the decision making in the future, however, the artificial intelligent algorithms will have to be finetuned to understand the impact the socio-cultural influences will have on the human decisions. We believe this study will help the designer of Industry 4.0 especially when designing the architecture with respect to vertical, horizontal and end-to-end integration because each human decision either external or internal to the organization can be analysed with respect to the dimensions of the study.

Though the sample appears small however it conforms to the suggested minimum sample size for IPA work (i.e. 10) if the respondent is regarded as one unit (Pietkiewicz \& Smith, 2014). The sample cannot be illustrative of employee's world over. It may be partly because the parameters of this population are unknown. Also, attaining a representative sample is not the purpose of most approaches to qualitative research (Pietkiewicz \& Smith, 2014). In its place, the goal of this study is to produce an in-depth analysis of the respondent's accounts of a small number of employees any conclusions that are specific to that group and any move beyond the group need caution. Among the other potential limitations in this study, it is important to mention the possibility of social desirability and memory decay affecting the data. To minimize the effects of social desirability-related apprehensions, an effort made is to create the relationship with respondent. This is with a specific objective to guarantee confidentiality to the research participants. The effects of memory decay are minimal through penetrating probing. It is also important to note, that these findings relate to employees employed in many capacities with substantial work experience and who were not discouraged from participating in the study by its sensitive topic. Thus, the findings and interpretations might not be reflective of those who do not fit into this profile. However, generalization was not the purpose of this qualitative study.

\section{FUTURE RESEARCH DIRECTION}

This research opens new vistas for exploring in the area of decision-making and the implication of technology effect on these hidden forces. Another interesting area for research would be to do comparatives studies at national, regional and global level. From the success, requirements and aspects of decision-making including financial impact in organizations research on how these hidden forces play out would be interesting. What areas of training need redesign to mitigate the consequential losses due to these hidden forces is also another interesting area and calls for attention?

\section{MANAGERIAL IMPLICATIONS}

This study explains the irrational behaviours of employees to cope with various activities or events happening at workplace. A central idea from this research would be to encourage positive irrational decision-making behaviours in employees if it is in line with organizational goals and objectives. Secularity in a desirable feature of the organization and therefore care may be taken, that such irrational behaviours does not spoil the secular environment of the organization. Managers can use the workplace irrational decision-making behaviours dimensions to understand the irrational behaviours of employees. Subsequently they can identify which dimension of workplace irrational decision-making behaviours in the employee is dominant. Religion is purported as an important tool in the organization (Khandwalla, 1972; Michael Sony \& Mekoth, 2017) and hence the dimension like religious based irrational decision-making behaviours which is harmless for the organization can be encouraged (Cash \& Gray, 2000). For example, if an employee prays to God or bows to some supernatural deity before he takes a major decision. The organization can permit such behaviours, however without disturbing the sentiments of others at the workplace. Nevertheless, employee needs 
to information that though organization per se does not discourage him or she from such positive irrational behaviour, but there is need to take care that other stakeholders are not hurt. In high stress, work situations, such irrational behaviours make be an important tool for organizations to manipulate. Sometimes it might also be a good idea to have some religious or holistic mechanisms to de-stress the employees or other stakeholders. E.g. If resources permit organizations can have a small place with the photograph of religious or other characters to build employees morale. Voluntary donations etc. by employees to various religious places may also be encouraged or religious events like annual Satya Narayana Puja (Vickers, 2016) may be encouraged during off-duty hours at workplace. However, a word of caution is to accommodate all prominent religions of the area where the organizations are located, else concentrating on only one religion may result in disharmony among employees. Organizations may also encourage their supervisors to find irrational behaviours among employees, which may not fit within organizational values and mission. Such employee irrational behaviours need explained to him or her so that in future such behaviours are not encouraged as it can result in huge financial losses. In other words, managers can try discouraging the negative aspect of workplace irrational decision-making behaviours and especially the ones which do not fit into organizational values and which disrupts peaceful atmosphere of the workplace. 


\section{REFERENCES}

Ananth, S. (n.d.). Conceptual Framework Of Vaastu. In New Architecture and Urbanism: Development of Indian Traditions. Cambridge Scholars Publishing. doi:10.5848/CSP.1892.00011

Anderson, J. D. (1921). Rain-Making in India. Folklore, 32(2), 123-124. doi:10.1080/0015587X.1921.9719187

Barber, C. L. (1964). The Form of Faustus' Fortunes Good or Bad. Tulane Drama Review, 8(4), 92. doi: $10.2307 / 1124921$

Barrett, J. L. (2007). Cognitive Science of Religion: What Is It and Why Is It? Religion Compass, 1(6), 768-786. doi:10.1111/j.1749-8171.2007.00042.x

Binde, P. (2007). Gambling and religion: Histories of concord and conflict. Journal of Gambling Issues, 20(20), 145-165. doi:10.4309/jgi.2007.20.4

Cash, K. C., \& Gray, G. R. (2000). A framework for accommodating religion and spirituality in the workplace. The Academy of Management Perspectives, 14(3), 124-133. doi:10.5465/ame.2000.4468072

Chung, R. C.-Y., \& Bemak, F. (2002). The Relationship of Culture and Empathy in Cross-Cultural Counseling. Journal of Counseling and Development, 80(2), 154-159. doi:10.1002/j.1556-6678.2002.tb00178.x

De Paola, M., Gioia, F., \& Scoppa, V. (2014). Overconfidence, omens and gender heterogeneity: Results from a field experiment. Journal of Economic Psychology, 45, 237-252. doi:10.1016/j.joep.2014.10.005

Dowling, M. (2007). From Husserl to van Manen. A review of different phenomenological approaches. International Journal of Nursing Studies, 44(1), 131-142. doi:10.1016/j.ijnurstu.2005.11.026 PMID:16412442

Eatough, V., \& Smith, J. A. (2017). Interpretative phenomenological analysis. The SAGE Handbook of Qualitative Research in Psychology, 193.

Evered, R. D., \& Selman, J. C. (1989). Coaching and the art of management. Organizational Dynamics, 18(2), 16-32. doi:10.1016/0090-2616(89)90040-5

Fincham, R., \& Evans, M. (1999). The consultants' offensive: Reengineering - from fad to technique. New Technology, Work and Employment, 14(1), 32-44. doi:10.1111/1468-005X.00051

Fingesten, P., Lehner, E., \& Whittlesey, E. S. (1975). Symbols, Signs and Signets. Leonardo, 8(3), 260. doi: $10.2307 / 1573261$

Frazer Winsted, K. (2000). Service behaviors that lead to satisfied customers. European Journal of Marketing, 34(3/4), 399-417. doi:10.1108/03090560010311920

Jha, J. T., \& Nanda, J. K. (2013). Corporate social responsibility: Employee perspective. International Journal of Productivity and Quality Management, 11(3), 311. doi:10.1504/IJPQM.2013.052947

Khandwalla, P. N. (1972). Environment and Its Impact on the Organization. International Studies of Management \& Organization, 2(3), 297-313. doi:10.1080/00208825.1972.11656125

Khresna Brahmana, R., Hooy, C.-W., \& Ahmad, Z. (2012). Psychological factors on irrational financial decision making: Case of day-of-the week anomaly. Humanomics, 28(4), 236-257. doi:10.1108/08288661211277317

Klostermaier, K. K. (2014). A concise encyclopedia of Hinduism. Oneworld Publications.

Koehn, A. (1954). Harbingers of Happiness. The Door Gods of China. Monumenta Nipponica, 10(1/2), 81. doi: $10.2307 / 2382793$

Kudler, D. (2012). The Seven Gods of Luck: A Japanese Tale (Vol. 1). Stillpoint Digital Press.

Lang, B., \& Leach, E. (1982). Social Anthropology. Man, 17(3), 578. doi:10.2307/2801746

Lazarus, R. S. (1995). Psychological stress in the workplace. Occupational Stress: A Handbook, 1, 3-14.

Lincoln, J. R., \& Kalleberg, A. L. (1985). Work Organization and Workforce Commitment: A Study of Plants and Employees in the U.S. and Japan. American Sociological Review, 50(6), 738. doi:10.2307/2095502 
Lo, J. C. (2003). Patients' attitudes vs. physicians' determination: Implications for cesarean sections. Social Science \& Medicine, 57(1), 91-96. doi:10.1016/S0277-9536(02)00301-5 PMID:12753818

Lykiardopoulos, A. (1981). The Evil Eye: Towards an Exhaustive Study. Folklore, 92(2), 221-230. doi:10.10 80/0015587X.1981.9716210

Mayer, A. C., Lewis, O., \& Barnouw, V. (1959). Village Life in Northern India: Studies in a Delhi Village. Pacific Affairs, 32(3), 330. doi:10.2307/3035137

Mehta, K. (1997). Cultural Scripts and the Social Integration of Older People. Ageing and Society, 17(3), 253-275. doi:10.1017/S0144686X97006430

Methuen, C. (2011). A History of Western Astrology, volume II:The Medieval and Modern Worlds, by Nicholas Campion. Reformation \& Renaissance Review, 13(1), 140-141. doi:10.1558/rrr.v13i1.140

Mitchell, N., \& Bhardwaj, S. M. (1975). Hindu Places of Pilgrimage in India: A Study in Cultural Geography. Geographical Review, 65(3), 417. doi:10.2307/213547

Naslund, D. (2008). Lean, six sigma and lean sigma: Fads or real process improvement methods? Business Process Management Journal, 14(3), 269-287. doi:10.1108/14637150810876634

Ng, T., Chong, T., \& Du, X. (2010). The value of superstitions. Journal of Economic Psychology, 31(3), 293-309. doi:10.1016/j.joep.2009.12.002 PMID:32287557

Patyal, V. S., \& Koilakuntla, M. (2016). Relationship between organisational culture, quality practices and performance: Conceptual framework. International Journal of Productivity and Quality Management, 19(3), 319. doi:10.1504/IJPQM.2016.079779

Payne, M. (2015). Modern social work theory. Oxford University Press.

Pfeilstetter, R. (2017). Anthropology and Social Work: Engagement with humans, moral dilemmas and theories of difference. European Journal of Social Work, 20(2), 167-178. doi:10.1080/13691457.2015.1131148

Pietkiewicz, I., \& Smith, J. A. (2014). A practical guide to using interpretative phenomenological analysis in qualitative research psychology. Psychological Journal, 20(1), 7-14.

Quaid, M. (1993). Job evaluation as institutional myth. Journal of Management Studies, 30(2), 239-260. doi:10.1111/j.1467-6486.1993.tb00303.x

Rengasamy, S., Devavaram, J., Marirajan, T., Ramavel, N., Rajadurai, K., Karunanidhi, M., Prasad, N. R., \& Erskine, A. (2003). Farmers' markets in Tamil Nadu: Increasing options for rural producers, improving access for urban consumers. Environment and Urbanization, 15(1), 25-34. doi:10.1177/095624780301500120

Samanta, S. (1994). The "Self-Animal" and Divine Digestion: Goat Sacrifice to the Goddess Kali in Bengal. The Journal of Asian Studies, 53(3), 779-803. doi:10.2307/2059730

Scandura, T. A. (2015). Essentials of organizational behavior: An evidence-based approach. SAGE Publications.

Shermer, M. (2002). Why people believe weird things: Pseudoscience, superstition, and other confusions of our time. Holt Paperbacks.

Smith, B. K., \& Doniger, W. (1989). Sacrifice and Substitution: Ritual Mystification and Mythical Demystification. Numen, 36(2), 189-224. doi:10.1163/156852789X00045

Sony, M. (2018). Industry 4.0 and lean management: A proposed integration model and research propositions. Production \& Manufacturing Research, 6(1), 416-432. doi:10.1080/21693277.2018.1540949

Sony, M., \& Mekoth, N. (2016). The relationship between emotional intelligence, frontline employee adaptability, job satisfaction and job performance. Journal of Retailing and Consumer Services. Retrieved from https://www. sciencedirect.com/science/article/pii/S0969698915301909

Sony, M., \& Mekoth, N. (2017). Workplace spirituality, frontline employee adaptability and job outcomes: An empirical study. International Journal of Process Management and Benchmarking, 7(4), 437-465. doi:10.1504/ IJPMB.2017.086925 
Sony, M., \& Naik, S. (2019). Key ingredients for evaluating Industry 4.0 readiness for organizations: a literature review. Benchmarking: An International Journal.

Stewart, P. J., \& Strathern, A. (n.d.). Witchcraft, Sorcery, Rumors, and Gossip. Cambridge University Press. doi:10.1017/CBO9780511616310.002

Stuckless, N., Ford, B. D., \& Vitelli, R. (1995). Vengeance, anger and irrational beliefs in inmates: A caveat regarding social desirability. Personality and Individual Differences, 18(1), 1-6. doi:10.1016/01918869(94)00134-E

Stueber, K. R. (2013). Empathy. Encyclopedia of Sciences and Religions. Springer Netherlands., doi:10.1007/9781-4020-8265-8_372

Su, H.-J., Lee, S., Ding, J., \& Comer, L. B. (2014). An Exploration into the Potential of Empathy for the Selection of Retail Employees. In New Meanings for Marketing in a New Millennium. Springer International Publishing. doi:10.1007/978-3-319-11927-4_12

Thomas, A. B. (2005). Controversies in management: Issues, debates, answers. Routledge. doi: $10.4324 / 9780203986929$

van den Heuvel, M., Demerouti, E., Bakker, A. B., \& Schaufeli, W. B. (2013). Adapting to change: The value of change information and meaning-making. Journal of Vocational Behavior, 83(1), 11-21. doi:10.1016/j. jvb.2013.02.004

Vickers, L. (2016). Religious freedom, religious discrimination and the workplace. Bloomsbury Publishing.

Wiseman, R., \& Watt, C. (2004). Measuring superstitious belief: Why lucky charms matter. Personality and Individual Differences, 37(8), 1533-1541. doi:10.1016/j.paid.2004.02.009

Michael Sony is faculty in Department of Mechanical \& Marine Engineering, Namibia University of Science \& Technology. He holds a PhD and Master of Engineering in Industrial Engineering from Goa University. He has vast Industrial Experience in Public and Private sector.

Neeta Baporikar is currently Director/Professor (Business Management) at Harold Pupkewitz Graduate School of Business (HP-GSB), Namibia University of Science and Technology, Namibia. Prior to this she was Head-Scientific Research, with Ministry of Higher Education CAS-Salalah, Sultanate of Oman, Professor (Strategic Management and Entrepreneurship) at IIIT Pune and BITS India. With more than a decade of experience in industry, consultancy and training, she made a lateral switch to research and academics in 1995. Dr. Baporikar holds D.Sc. (Management Studies) USA, PhD in Management, University of Pune INDIA with MBA (Distinction) and Law (Hons.) degrees. Apart from this, she is also an External Reviewer, Oman Academic Accreditation Authority, Accredited Management Teacher, Qualified Trainer, Doctoral Guide and Board Member of Academics and Advisory Committee in accredited $B$-Schools. Reviewer for international journals, she has to her credit several conferred doctorates, several refereed research papers, and authored books in the area of Entrepreneurship, Strategy, Management and Higher Education. 